\title{
Perianal fistulas and the lift procedure: results, predictive factors for success, and long-term results with subsequent treatment
}

\author{
G. J. H. Vander Mijnsbrugge' ${ }^{1}$ R. J. F. Felt-Bersma ${ }^{1,2}$ (1) D. K. F. Ho ${ }^{2}$ C. B. H. Molenaar ${ }^{1}$
}

Received: 8 November 2018 / Accepted: 20 June 2019 / Published online: 17 July 2019

(c) The Author(s) 2019

\begin{abstract}
Background Treatment of a perianal fistula is difficult due to the risk of fecal incontinence and recurrence. The ligation of intersphincteric tract (LIFT) procedure is a sphincter-saving procedure associated with success rates ranging from 57 to $94 \%$. The aim of our study was to find predictors for a favorable outcome of the LIFT procedure, evaluation of postoperative fecal incontinence, quality of life, and subsequent treatment with long-term follow-up.

Methods This study was performed in patients who underwent LIFT between 2013 and 2015 at our institution. Their medical data were retrieved from the electronic patient files. The fistula characteristics were described by physical examination, three-dimensional endoanal ultrasound, and perioperative evaluation. Recurrence rate, postoperative fecal incontinence, and quality of life were assessed with the Patient-Reported Outcome Measurement (PROM). Thirty-two months later, long-term follow-up including subsequent procedures was evaluated.

Results Forty-five patients [17 men, mean age 40 years (range 24-67 years)] were included. In 41 (84\%) patients, the fistula was classified as complex; $32(71 \%)$ were referrals with a history of previous fistula surgery. The initial success rate was 18 (40\%). Only the height of the internal fistula opening $(\geq 15 \mathrm{~mm} p<0.03)$ was associated with recurrence. The LIFT procedure did not affect the occurrence of fecal incontinence or soiling. Recurrence showed a trend with a lower PROM $(p=0.07)$. Twenty-four months later, further surgery leads to cure in 34 (75\%), asymptomatic fistulas in 7 (16\%), and persisting active fistulas in 4 (9\%) patients.

Conclusions Initial LIFT had a success rate of $40 \%$ and with subsequent surgical treatment $75 \%$. Recurrence after LIFT is related to the height of the internal fistula opening and is associated with diminished quality of life. Continence was not affected by initial LIFT.
\end{abstract}

Keywords Anorectal disease $\cdot$ Perianal fistula $\cdot$ Anal ultrasound $\cdot$ LIFT

\section{Introduction}

A perianal fistula is an abnormal connection between the perianal skin and the anal canal or rectum [1]. It is probably an inflammatory condition in which infection begins in one

Part of this study was presented at the Dutch Society of Gastroenterology (NVGE) on March 23-24th 2016, Veldhoven, The Netherlands.

\footnotetext{
R. J. F. Felt-Bersma

rjf.felt@amsterdamumc.nl

1 Proctos Kliniek, Bilthoven, The Netherlands

2 Department of Gastroenterology and Hepatology, Amsterdam UMC, Location VUmc, P.O. Box 7057, 1007 MB Amsterdam, The Netherlands
}

of the 6-10 rudimental anal glands [2]. Recent insights suggest possible immunologic causes of a fistula [3].

Fistula treatment is complex due to possible recurrence and sphincter damage leading to soiling and fecal incontinence (FI). Laying open the tract by fistulotomy is still considered the most effective procedure. However, postoperative incontinence has been reported ranging from 4 to $62 \%$ and occurs generally around $13 \%$ [4]. For high and more complex fistulae (CF), approaches such as mucosal advancement flap (MAP) are recommended as the continence mechanism is more likely to become impaired after fistulotomy.

Primary fistulotomy and cutting setons are associated with the same incidence of GI depending on the complexity of the fistula, ranging from 25.2 to $67 \%$ [5, 6]. Although the aim of a surgical procedure is to cure a fistula, conservative management is sometimes warranted to preserve FI. 
However, trading radical surgery for sphincter-saving procedures such as a draining seton, fibrin sealant, anal fistula plug, and laser and Permacol ${ }^{\circledR}$ instillation all result in more recurrence/persistence requiring repeated operations in many cases [7].

The ligation of intersphincteric fistula tract (LIFT) technique is the modified approach through the intersphincteric plane for the treatment of fistula-in-ano. The LIFT procedure is based on secure closure of the internal opening through the intersphincteric approach. Essential steps of the procedure include incision at the intersphincteric groove, identification of the intersphincteric tract, ligation of intersphincteric tract close to the internal opening, and removal of intersphincteric tract. Subsequently, the defect at the external sphincter muscle is sutured. The procedure was first described by Rojanasakul in 2007 [8, 9]. His preliminary results in terms of the success of this procedure were $94 \%$. Later, several centers reported lower success rates. Although there are several studies about the recurrence rate after LIFT, data about incontinence and quality of life after LIFT are scarce. Furthermore, there is no consistency in the definition of the complexity of the treated fistulas and not much is known about the effect of certain specific characteristics such as the location of the internal fistula opening (IFO), the height of the IFO measured from the ano-dermal junction, and use of certain surgery techniques, e.g., ligation versus suturing of the fistula tract on the outcome.

The aim of this study was to determine if these specific characteristics are relevant to the outcome of recurrence, FI, and quality of life (QOL), and the long-term outcome after subsequent procedures.

\section{Materials and methods}

\section{Patients and clinic}

The Proctos clinic is specialized in proctologic surgery and serves as a referral clinic.

Inclusion criteria were all consecutive patients with perianal fistulas who were treated with an LIFT procedure within the period of January 2013 (when the clinic started using the procedure) to December 2015. Treatment was offered based on shared decision-making.

Exclusion criteria were patients with an intersphincteric fistula, an abscess, rectovaginal fistulas, fistula due to a pilonidal sinus, hidradenitis suppurativa, tuberculosis, human immunodeficiency virus infection, inflammatory bowel disease, actinomycosis, and anal carcinoma.

Data were gathered from the electronic patient file regarding demographics, symptoms, medical history, previous perianal surgical procedures, obstetric history, and findings of the proctological examination at first presentation.

\section{Three-dimensional endoanal ultrasound (3D-EAUS)}

Physical examination was performed with the patient in the left lateral decubitus position. 3D-EAUS was performed using a 3D-EAUS system (Hawktype 2050, B-K Medical, Naerum, Denmark) with a rotating endoprobe housing two crystals covering $10-16 \mathrm{MHz}$ (focal range $2-4.5 \mathrm{~cm}$; diameter, $1.7 \mathrm{~cm}$ ) and producing a $360^{\circ}$ view and with an internal puller allowing longitudinal distances to be measured and a constructing a 3D image.

The fistula tract appeared as a hypoechoic tube-like lesion. If an external fistula opening was present, $2 \%$ hydrogen peroxide was introduced into the fistula track using a flexible intravenous cannula. The site of the IFO was identified as a sub-epithelial breach connected to an internal sphincter defect, or as a root-like budding which is in contact with, or is positioned inside the internal anal sphincter. This was according to the Cho criteria for identifying the IFO of an anal fistula tract [10]. The height of the IFO was measured starting from the anal verge. Preoperatively fistulae were classified as intersphincteric, low transsphincteric (involving the lower $1 / 3$ of the sphincter complex), mid transsphincteric (involving the middle $2 / 3$ of the sphincter complex), high transsphincteric (involving the highest $1 / 3$ of the sphincter complex), suprasphincteric, or extrasphincteric. A fistula was considered complex if there were multiple fistula tracts or a mid/high transsphincteric, suprasphincteric, or extrasphincteric fistula tract. Low transsphincteric were classified as simple fistulas.

\section{Fecal incontinence (FI)}

Preoperatively FI was assessed by the patient's ability to hold solid stool, liquid stool, flatus, and soiling. This was determined by the patients' history performed by a surgeon and was classified using the Parks FI classification [2]. Postoperative FI was evaluated by means of a paper questionnaire in December 2015 and by face-to-face contact or telephone in 2018.

\section{Surgical procedure}

The patients arrived on the day of surgery. No bowel preparation or antibiotics were given prior to the surgery. The LIFT procedure was performed under general anesthesia. Essential steps of the procedure include incision at the intersphincteric groove, identification of the intersphincteric portion of the tract, thorough cleaning of the tract, ligation of intersphincteric tract close to the internal opening, removal of intersphincteric portion of the tract, core out of the external tract and the external opening, and suturing of the defect 
at the intersphincteric site of the external sphincter muscle, and the external opening was left open for discharge. The classic approach had to be modified if the tract could not be dissected safely (a very thick tract, too much fibrosis around the tract, proximal curving of the tract, and immediate branching of the tract at the intersphincteric site). The intersphincteric tract was then cut rather than dissected, and after removal of the intersphincteric portion of the tract, the tract was sutured. The suture was placed at the level of the internal sphincter muscle.

To verify that the fistula tract was closed, hydrogen peroxide was introduced into the IFO during the operation.

The patients were discharged the same day of surgery. Paracetamol and ibuprofen were prescribed for pain management.

\section{Follow-up}

Patients were seen 2 weeks after the initial procedure by their surgeon.

The next consultations were at 4-weekly intervals until recurrence or complete healing had occurred.

The initial follow-up period with extensive questionnaires was from the first perianal fistula-related surgery up to December 2015.

The second follow-up was in September 2018 to evaluate recurrence and complaints only. The electronic patient files were reviewed and the checked for recurrences. If the patient was not seen during the previous 3 months, a telephone call was made.

A recurrence was defined as a persisting fistula opening after 3 months or a new fistula after the initial closure.

\section{Questionnaires}

In December 2015, questionnaires regarding the current fistula-related perianal symptoms, complaints of fecal incontinence, and the impact of current fistula-related complaints on QOL (Procto-PROM) were sent out to all the participants. Current fistula-related complaints were defined as perianal pain, tenderness, or fistula-related pus secretion. If a patient did not return the first set questionnaires, they were sent a second set.

A patient-reported outcome measurement or PROM is a validated questionnaire used in a clinical trial or a clinical setting, where the responses are collected directly from the patient. Evidence shows that the systematic use of information from PROMs leads to better communication and decision-making between doctors and patients and improves patient satisfaction with care [11-13]. The validated ProctoPROM questions were divided in five categories: daily life, stool related, social life, coping, relationships, and intimacy. The maximum score per category is 10 points with a total score of 50 points. The higher the score, the more impact the symptoms have per category.

\section{Statistical analysis}

Data were analyzed using the Statistical Packages for Social Sciences (SPSS, Chicago, IL, USA, version 22.0). Univariate analysis was performed on factors possibly associated with recurrence. Associations between groups were compared using the Chi-square, paired $t$ test, or one-way ANOVA. A $p$ value $<0.05$ was considered to be statistically significant.

\section{Ethical issues}

The study was approved by the Medical Ethical Committee of the VU University Medical Centre.

\section{Results}

A total of 268 patients with perianal fistula were seen between June 2-13 and December 2015, from which 45 (17\%) were treated with the LIFT procedure, 145(54\%) with fistulotomy, 37 (14\%) with a seton, 11 (4\%) with fistulectomy, 11 (4\%) with MAP, 11 (4\%) with fistulectomy, 9 (3\%) with Permacol, 7 (3\%) with at excision of the external fistula opening, and 3 (1\%) with bio-lift (Fig. 1).

All 45 patients were included (Table 1). There were 17 males (38\%). Mean age was 40 years (range 24-67 years). Thirteen $(29 \%)$ patients presented with a first fistula. Thirty-two patients (71\%) had had previous fistula surgery, all had a seton and abscess drainage, and in 16 patients, 20 additional procedures were performed (MAP $n=6$, fistulotomy $n=5$, plug $n=4$, fistulectomy $n=2$, Permacol ${ }^{\circledR}$ paste $n=1$, excision external opening $n=1$, and temporary stoma $n=1$ ).

There were three diabetic patients using oral medication. Three patients smoked. One patient had a body mass index $>30 \mathrm{~kg} / \mathrm{m}^{2}$. None had an enterostomy.

The mean operation time was $67 \mathrm{~min}$ (range 22-140 min). The first operations took longer due to the learning curve. There was no postoperative bleeding or infection.

The mean follow-up time for the questionnaires was 12 months [SD 0.5, (range 6-24 months)].

The classification of the fistulas is shown in Table 2. In 41 (91\%) patients, a CF was present. The patients with mid and high transsphincteric fistulas all had secondary tracts or an extension higher than the internal opening. 
Fig. 1 Flow diagram of treatment of patients with perianal fistulas in the period June 2013 Dec 2015

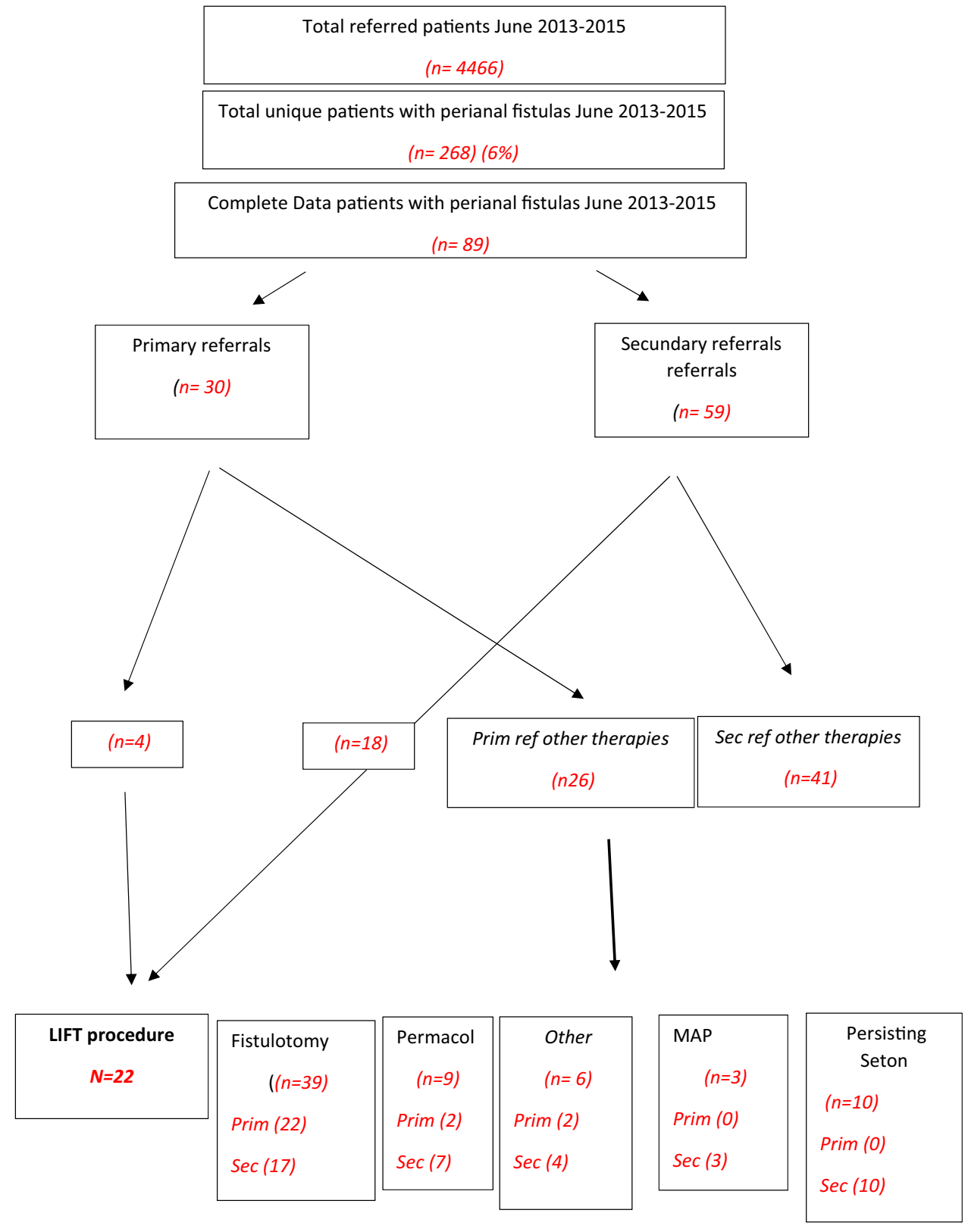

\section{Results}

\section{Questionnaires evaluation: December 2015}

From the 45 patients included, 32 (71\%) patients returned the questionnaire. Three patients refused to fill in the questionnaire and ten patients could not be contacted. The mean follow-up at this point was 12 months (SD 0.5, median 13 months, range 7-24 months)

FI Preoperatively, eight patients had existing FI, seven had a history of fistula-related surgery, and one had a previous seton and abscess drainage only. Three women and one man were incontinent for solid stool (Parks 4), two men and one woman for liquid stool (Parks 3), and one man for flatus (Parks 2). Three men had soiling due to a keyhole deformation. Postoperatively, their Parks score was unaltered and no additional symptoms of soiling were reported.

QOL (Prom) There was a negative effect of a CF (simple 5.8 and complex $13.9(p<0.01)$ and a trend with recurrence of the fistula (no recurrence 8.8 and recurrence $14.9 p=0.07$ ) on the QOL.

\section{Recurrences}

Figure 2 shows a flow sheet of the results. Recurrences occurred after a mean of 3 months (0.5-12 months). 
Table 1 Patients characteristics in 45 cryptoglandular fistulas

\begin{tabular}{llll}
\hline & All & No recurrence & Recurrence \\
\hline All & 45 & $18(40 \%)$ & $27(60 \%)$ \\
Man & 17 & $2(11 \%)^{\mathrm{t}}$ & $15(89 \%)^{\mathrm{tt}}$ \\
Woman & 28 & $16(57 \%)^{\mathrm{t}}$ & $12(43 \%)^{\mathrm{t}}$ \\
Age (mean, years) & 40 & 39 & 40 \\
History & & & \\
No previous fistula surgery & $13(29 \%)$ & 5 & 8 \\
Previous fistula surgery & $32(71 \%)$ & 13 & 19 \\
Seton + drainage & 16 & 7 & 9 \\
Seton + drainage + other & 16 & 6 & 10 \\
\hline
\end{tabular}

${ }^{\mathrm{t}} p=0.004$

${ }^{a}$ Other: mucosal advancement flap 6, fistulotomy 5, plug 4, fistulectomy 2 , Permacol ${ }^{\circledR}$ paste 1 , excision external opening 1 , and temporary stoma 1

Table 2 Classification and closure technique of the 45 fistulas related to recurrence

\begin{tabular}{llll}
\hline Type fistula & $\begin{array}{l}\text { All } \\
45\end{array}$ & $\begin{array}{l}\text { No recurrence } \\
18\end{array}$ & $\begin{array}{l}\text { Recurrence } \\
27\end{array}$ \\
\hline Classification tracts & & & \\
1. Transsphincteric (low) & $4(9 \%)$ & 1 & 3 \\
2. Transsphincteric (mid) & $5(11 \%)$ & 2 & 3 \\
3. Transsphincteric (high) & $34(76 \%)$ & 14 & 20 \\
4. Ano-introital & $2(4 \%)$ & 1 & 1 \\
Simple or complex & & & \\
Simple (1) & $4(9 \%)$ & 1 & 3 \\
Complex (2-4) & $41(91 \%)$ & 17 & 24 \\
Location IFO & & & \\
Anterior & $27(60 \%)$ & 12 & 15 \\
Posterior & $14(31 \%)$ & 4 & 10 \\
Right lateral & $2(4 \%)$ & 1 & 1 \\
Left lateral & $2(4 \%)$ & 1 & 1 \\
Height IFO & $(16.1 \mathrm{~mm})$ & $(13.3 \mathrm{~mm})$ & $(18.5 \mathrm{~mm})$ \\
$\geq 20$ mm & 13 & $3(23 \%)^{\#}$ & $10(77 \%)^{\#}$ \\
$\geq 15$ mm & 28 & $8(29 \%)^{\Delta}$ & $20(71 \%)^{\Delta}$ \\
Closure technique & & & 10 \\
Suture & $16(35 \%)$ & 8 & 18 \\
Ligation & $29(65 \%)$ & 11 & \\
\hline
\end{tabular}

IFO internal fistula opening

${ }^{\#} p<0.03$

${ }^{\Delta} \mathrm{p}<0.03$

\section{Evaluation: December 2015}

Of the 45 patients, 18 (40\%) were successfully cured after the first LIFT procedure and 27 (60\%) experienced a recurrence. The demography and fistula classification of the patients with and without recurrence are shown in Tables 1 and 2. There were no statistically significant differences between the two groups concerning, age, previous fistula treatment, the complexity of fistula tract(s), the surgical technique of suture versus ligation, the clockwise orientation of the IFO, and the duration of the placement of a seton.

Men more had more recurrences then women $(89 \%$ and $43 \%, p<0.04)$.

A higher IFO had a higher chance of recurrence $(13.3 \mathrm{~mm}$ in non-recurrence and $18.5 \mathrm{~mm}$ in recurrence, $p=0.05$ ), especially when the IFO was situated $\geq 15 \mathrm{~mm}$ above the ano-dermal junction $(\mathrm{RR}=0.34 \% \mathrm{CI} 0.12-0.99 p=0.030)$.

The mean height of the IFO in men was $17.3 \mathrm{~mm}$ and women $15.1 \mathrm{~mm}(p=0.09)$.

Of the 27 recurrences, 9 (33\%) were downgraded (on clinical examination and EUS) to a lower transsphincteric (1) or intersphincteric (8) fistula without an extra branch (Table 3).

\section{Long-term evaluation: September 2018}

All but two patients could be contacted (96\%). Of the patients who were lost to follow-up, one had a persisting asymptomatic fistula and one had an active fistula without complaints who moved abroad. Their last follow-up was in 2017.

The mean follow-up was 45 months (median 46 months; range 40-57 months).

Both the cure rate and the amount of subsequent procedures did not differ between downgraded or unaltered fistulas (Table 3, Fig. 2).

After the initial cure after LIFT of $18(40 \%)$ patients in 2015 , further surgery with the other techniques lead to cure in $34(75 \%)$, and asymptomatic fistulas in $7(16 \%)$ and 4 (9\%) in 2018. Two patients treated additionally with a fistulotomy developed minor soiling.

\section{Discussion}

The success rate for the initial cure in our study was low: $40 \%$. Of the 27 recurrences, downgrading occurred in 9 $(33 \%)$. All recurrences were subsequently treated with (several) subsequent procedures (Table 3, Fig. 2), which resulted in a healed fistula in another 16 patients and asymptomatic fistulas in 7 patients. Looking at the original group of 45 patients, ultimately $75 \%$ were cured, $16 \%$ had asymptomatic fistulas, and $9 \%$ had persisting fistulas.

Although, in $60 \%$ of the cases, the fistula did not resolve after the first operation, down-staging of the complexity of the fistula was obtained in 30\%. The importance of downgrading is that the remaining fistula tract is easier to treat. In general, a fistulotomy can be performed with little risk of FI. 


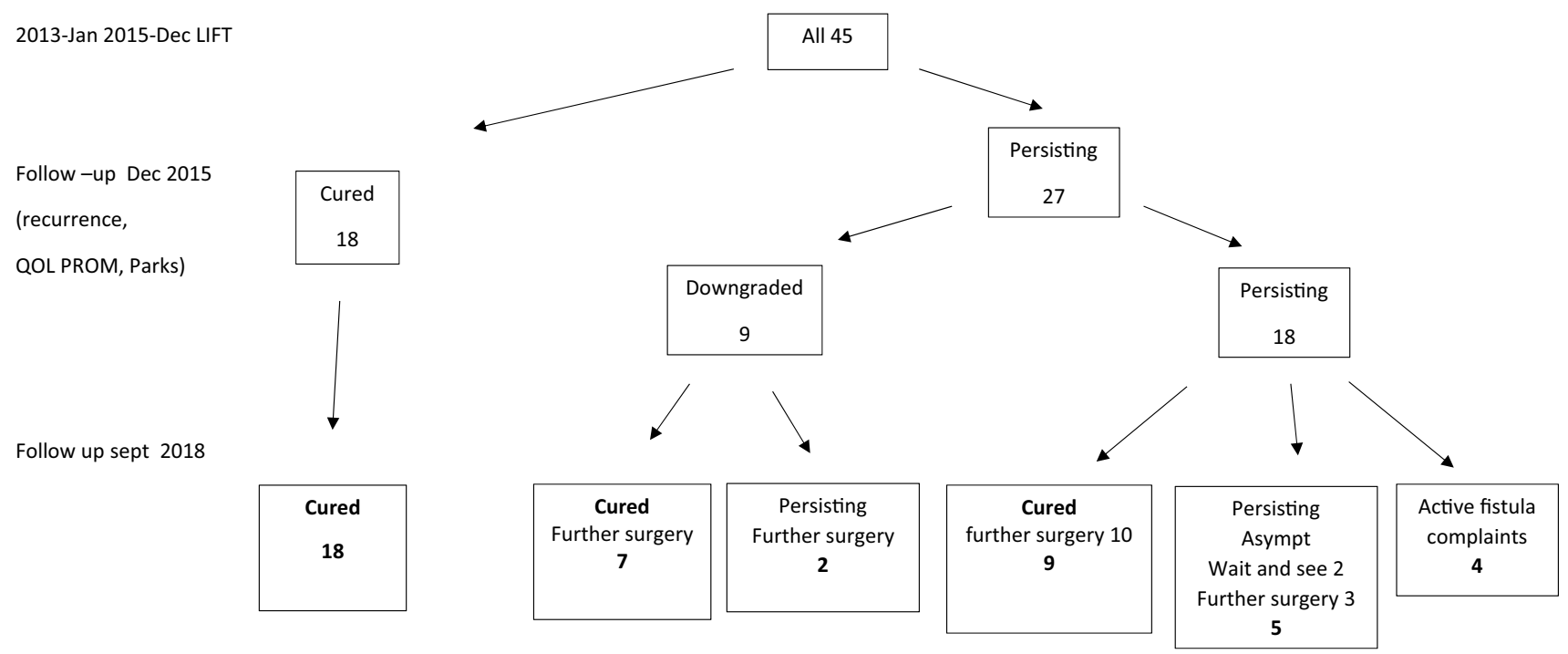

Fig. 2 Flow sheet of Patients and follow-up of the questionnaires in to cure in 34 (75\%), asymptomatic fistulas in $7(16 \%)$, and persisting 2015 and telephone call long-term follow-up in 2018. The initial cure active fistulas in $4(9 \%)$

Table 3 Recurrences and follow-up in 27 patients with cryptoglandular fistulas

\begin{tabular}{|c|c|c|c|c|c|c|c|}
\hline \multicolumn{2}{|c|}{$\begin{array}{l}\text { Pre-LIFT fistula classification in } \\
\text { patients with recurrence }\end{array}$} & \multicolumn{2}{|c|}{$\begin{array}{l}\text { Post-LIFT fistula classification in } \\
\text { patients with recurrence Dec } 2015\end{array}$} & \multicolumn{4}{|l|}{$\begin{array}{l}\text { Post-LIFT } \\
\text { Sept } 2018\end{array}$} \\
\hline Fistula type & All 27 & $\begin{array}{l}\text { Unaltered } 18 \\
(67 \%)\end{array}$ & Downgraded $9(33 \%)$ & Treatment follow-up & $\begin{array}{l}\text { Cured } \\
17(61 \%)\end{array}$ & $\begin{array}{l}\text { Asym } \\
8(29 \%)\end{array}$ & $\begin{array}{l}\text { Fistula } \\
3(10 \%)\end{array}$ \\
\hline Transsphincteric (low) & 3 & 2 & 1 inter & $\begin{array}{l}1 \mathrm{~S}, \mathrm{~F} \\
1 \mathrm{~S}, \text { re-lift, } \mathrm{PP}, \mathrm{S} \\
1 \mathrm{MAP}, \text { asympt. }\end{array}$ & 1 & $\begin{array}{l}1 \\
1\end{array}$ & \\
\hline Transsphincteric (mid) & 3 & 1 & 2 inter & $\begin{array}{l}1 \text { bio-lift } \\
1 \mathrm{~F} \\
1 \text { asymp. }\end{array}$ & $\begin{array}{l}1 \\
1\end{array}$ & 1 & \\
\hline Transsphincteric (high) & 20 & 14 & $\begin{array}{l}5 \text { inter } \\
1 \text { trans mid }\end{array}$ & $\begin{array}{l}14^{\mathrm{a}}\left(4^{\mathrm{b}}\right) \\
2 S(2 x), F \\
1 S, P P, \text { asymp. } \\
1 F \\
1 P P \\
1 F\end{array}$ & $\begin{array}{l}6\left(3^{b}\right) \\
2\end{array}$ & $\begin{array}{l}4\left(1^{b}\right) \\
1\end{array}$ & 4 \\
\hline Ano-introital & 1 & 1 & 0 & Re-lift, bio-lift & 1 & & \\
\hline
\end{tabular}

The 9 downgraded fistulas: 7 (78\%) cured and 2 (22\%) asymptomatic; 18 unaltered fistulas 9 (50\%) were cured, 5 (28\%) asymptomatic, and 4 (22\%) persistent fistula

$S$ seton, $F$ fistulotomy, MAP mucosal advancement, $P P$ Permacol paste

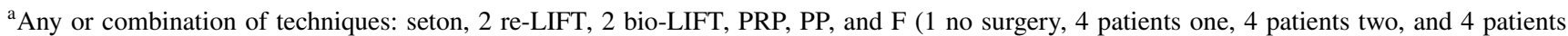
three surgeries)

${ }^{\mathrm{b}}$ Patients with (Bio)Lift

The italic fistulas are the downgraded fistulas

Other centers have had the same experience [14]. There was a trend towards a higher healing rate and less subsequent procedures between the downgraded and unaltered fistulas.
Our results seem disappointing compared to the results in the literature, where the success rates are generally higher. Table 4 shows a review of the published studies 
Table 4 LIFT procedure in series $>35$ patients

\begin{tabular}{|c|c|c|c|c|c|c|c|c|}
\hline Author & Year & $N(\%$ male $)$ & $\begin{array}{l}\text { Complex } \\
\text { Fistula } \\
(\%)\end{array}$ & $\begin{array}{l}\text { Other fistula classification } \\
\text { complex }\end{array}$ & $\begin{array}{l}\text { Previous } \\
\text { surgery } \\
(\%)\end{array}$ & $\begin{array}{l}\text { Previous } \\
\text { seton } \\
(\%)\end{array}$ & Success rate $(\%)$ & Follow-up (months) \\
\hline Bleier & 2010 & $39(51 \%)$ & 25 & hs, high & 74 & - & 57 & 5 \\
\hline Shanwani $^{c}$ & 2010 & $45(71 \%)$ & 27 & $>30 \%$ Sphincter & 11 & - & $64 \mathrm{r}$ & $9(2-16)$ \\
\hline Tan & 2011 & $93(83 \%)$ & 58 & High and $\mathrm{mt}$ & 28 & - & 78 & 5.8 \\
\hline Abcarian & 2012 & $40(?)$ & - & - & 75 & - & 74 & 4.2 \\
\hline Wallin & 2012 & $93(61 \%)$ & $\begin{array}{l}17 \mathrm{hs} \\
26 \mathrm{mt}\end{array}$ & $\begin{array}{l}\mathrm{hs} / \mathrm{mt} \\
>35 \% \text { sphincter }\end{array}$ & 32 & 92 & $\begin{array}{l}40 \text { in } \\
57^{\mathrm{a}}\end{array}$ & $19(4-55)$ \\
\hline Liu & 2013 & $38(74 \%)$ & - & Length of fistula tract & 18 & 76 & 62 in & $\begin{array}{l}26(3-44) \\
68 \%>12\end{array}$ \\
\hline Bastawrous & 2015 & $56(76 \%)$ & - & - & 52 & 55 & $\begin{array}{l}71 \text { in } \\
65 \mathrm{r}\end{array}$ & 4.8 \\
\hline Parthasarathi ${ }^{\mathrm{c}}$ & 2015 & $167(81 \%$ & All & $>1 / 3$ Sphincter or branches & 33 & - & 94 & $12(4-22)$ \\
\hline Schultze $^{c}$ & 2015 & $75(68 \%)$ & All & $>30 \%$ Sphincter & 48 & - & $88 \mathrm{r}$ & 14.6 \\
\hline Chen & 2017 & $43(74 \%)$ & 33 & $\mathrm{hs} / \mathrm{mt}$ & 28 & - & $84^{\mathrm{a}}$ & $26(13-63)$ \\
\hline $\mathrm{Xu}$ & 2017 & $55(64 \%)$ & All & $\mathrm{hs} / \mathrm{mt}$ & 100 & - & $60 \mathrm{r}$ & 16 \\
\hline Wen $^{\mathrm{b}}$ & 2018 & $62(69 \%)$ & - & 41 ht, $4 \mathrm{H}$ int.sph, 17 Ant Fe & 29 & - & 84 & $24(12-51$ \\
\hline Sun & 2019 & $70(84 \%)$ & All & High: above subcut ext sphincter & 24 & - & $\begin{array}{l}81 \\
67 \mathrm{r}\end{array}$ & $16(4.5-68)$ \\
\hline Mijnsbrugge & 2019 & $45(38 \%)$ & 91 & $\begin{array}{l}>1 / 3 \text { Sphincter or branches } \\
\text { height of IO }\end{array}$ & 71 & 71 & $\begin{array}{l}40 \\
75^{\mathrm{a}}\end{array}$ & $45(40-57)$ \\
\hline
\end{tabular}

- not clearly indicate, $h s$ horseshoe, $h t$ high transsphincteric, $m t$ multiple tracts, io internal opening, in initial cure, $r$ cure after recurrence

${ }^{\mathrm{a}}$ Cure or downgraded with subsequent surgery

${ }^{\mathrm{b}}$ Modified LIFT

${ }^{\mathrm{c}}$ Prospective

including $>35$ patients [14-25]. A systematic review in 2016 [26] evaluated articles with perineal procedures and found 19 appropriate articles with an overall success rate of $51-94 \%$. Ten of these studies had less than 35 patients, five were prospective, and only three studies had a follow-up longer than 1 year.

What is the explanation for such a diversity in success?

First, the definition of complex and simple fistulas and the number of included CF. This is not always mentioned. The definition involves the height of the fistula and side branches. We had 91\% CF; almost all transsphincteric fistulas were very high (involving the highest $1 / 3$ of the sphincter complex) (Table 2). Furthermore, most investigators use the lowest $1 / 3$ of the sphincter complex as a starting point for high fistulas. Finally, our fistulas had extensions or side branches above the IFO. Recurrences have been related to complexity of fistulas [24, 27, 28].

Second, the mean follow-up in the literature did not always reach 6 months and even less studies had a followup of more than 1 year. Although most recurrences occur within 6 months, many individual patients were followed for less than 6 months.

Third, the definition of success differs between different studies. The initial closure is often noted as success and not the corrected number after subsequent recurrences. Furthermore, whether cure occurred after subsequent treatments is not always clear.

Fourth, we had a high percentage of previously operated patients many of whom had undergone more than 1 procedure. Recurrence has been related to past fistula surgery [24, 27, 28].

Besides the previous surgery, several other factors have been associated with recurrence. Unexplored secondary tracts are a well-known cause [27]. With EUS or magnetic resonance imaging (MRI) before surgery, missed tracts are generally avoided. There is some discussion about surgery being the golden standard to evaluate secondary tracts, but studies with anal ultrasound and MRI have demonstrated that tracts found with these modalities can be missed during surgery. EAUS is an easy to use bedside tool providing excellent visualization of the fistula tracts [29]. The length of the fistula [15], lateral localization of the IFO [28], diabetes, smoking, and obesity $[15,18,22,27]$ have also been mentioned as possible causes of recurrence or failure.

The previous treatment with a seton is still a matter of debate. Epithelialization of the tract as a result of seton placement seems logical, but has not been demonstrated [30] and has been associated with failure [21]. 
Antibiotics were not used in our study. The role of concomitant infection is controversial. The use of antibiotics or core out $[22,24,27]$ has been successful in some cases, but is not generally applied. Most studies do not mention the use of antibiotics and no clear evidence exists concerning recurrence. [24].

The only predictor which we found for recurrence was the height of the IFO. We believe that the height of the IFO is crucial in the definition of the complexity of the fistula. In our study, $76 \%$ of the fistulas were classified as high transsphincteric. The unexpected finding that men had more recurrences than women was possibly due to the higher IFO in men. Although persistence or recurrence is disappointing, subsequent surgery can often cure the fistula $[14,15]$.

The LIFT procedure did not lead to genuine FI; two patients developed soiling due to subsequent fistulotomy after downgrading with LIFT. Other studies report similar experiences [19, 21, 23].

The PROM (QOL) score was lower in patients with recurrence and a CF. We used a PROM questionnaire, since this is now a routine procedure in our clinic before and after treatment. The FI QOL scale is also a good tool [31], but does not reflect the real disease burden with problems in fistula surgery.

This retrospective study has some limitations. Although our prospective database is very extended and precise, the questionnaires were not applied before surgery at that time. Furthermore, the response of $71 \%$ to the questionnaires is suboptimal. However, in 2018, all records were studied again and checked for recurrences, FI and soiling; when patients had not been seen for than 3 months, they were reached by telephone

The importance of this study is that it shows again that initial success rates of treatment in patients with perianal fistulas are overrated and studies should be repeated by the other groups to confirm the success rate. The commonly heard saying that complicated fistulas have a recurrence of $50 \%$ independently of the technique used seems true. Furthermore, this study shows that, by combining techniques, cure or asymptomatic fistulas can be achieved in almost all patients.

\section{Conclusions}

The only predictive factor for recurrence with LIFT was the height of the IFO especially if located $\geq 15 \mathrm{~mm}$ from the anal verge.

Continence was preserved and incontinence did not worsen in patients who had already complaints. Recurrences and complexity of the fistula were negatively associated with FI and QOL.
Author contributions GJHVM performed the surgery, designed the study, drafted the work, and gave intellectual input. RJFF-B designed the study, drafted the work, wrote the final version, and gave intellectual input. DKFH performed data acquisition and first draft of the article. CBHM performed the surgery, designed the study, drafted the work, and gave intellectual input.

Funding There was no financial support for this study.

\section{Compliance with ethical standards}

Conflict of interest All the authors declare that they have no conflict of interest.

Ethical approval We declare that there are no ethical issues.

Informed consent All patients gave informed consent as part of the procedure.

Open Access This article is distributed under the terms of the Creative Commons Attribution 4.0 International License (http://creativeco mmons.org/licenses/by/4.0/), which permits unrestricted use, distribution, and reproduction in any medium, provided you give appropriate credit to the original author(s) and the source, provide a link to the Creative Commons license, and indicate if changes were made.

\section{References}

1. Malik A, Hall D, Devaney R, Sylvester H, Yalamarthi S (2011) The impact of specialist experience in the surgical management of perianal abscesses. Int J Surg 9(6):475-477

2. Parks AG, Gordon PH, Hardcastle JD (1976) A classification of fistula-in ano. Br J Surg 63(1):1-12

3. Ratto C, Litta F, Lucchetti D, Parello A, Boninsegna A, Arena V, Donisi L, Calapà F, Sgambato A (2016) Immunopathological characterisation of crypto glandular anal fistula: a pilot study investigating the pathogenesis. Colorectal Dis 12:436-444

4. Ratto C, Litta F, Donisi L, Parello A (2015) Fistulotomy or fistulectomy and primary sphincteroplasty for anal fistula (FIPS): a systematic review. Tech Coloproctol 19(7):391-400

5. Garcia-Aguilar J, Belmonte C, Wong WD, Goldberg SM, Madoff RD (1996) Anal fistula surgery. Factors associated with recurrence and incontinence. Dis Colon Rectum 39:723-729

6. Vial M, Parés D, Pera M, Grande L (2010) Faecal incontinence after seton treatment for anal fistulae with and without surgical division of internal anal sphincter: a systematic review. Colorectal Dis 12(3):172-178

7. Dudukgian H, Abcarian H (2011) Why do we have so much trouble treating anal fistula? World J Gastroenterol 17(28):3292-3296

8. Rojanasakul A, Pattanaarun J, Sahakitrungruang C, Tantiphlachiva K (2007) Total anal sphincter saving technique for fistulain-ano; the ligation of intersphincteric fistula tract. J Med Assoc Thai 90(3):581-586

9. Rojanasakul A (2009) LIFT procedure: a simplified technique for fistula-in-ano. Tech Coloproctol 13(3):237-240 (Epub 2009 Jul 28)

10. Cho DY (1999) Endosonographic criteria for an internal opening of fistula-in-ano. Dis Colon Rectum 42:515-518

11. Marshall S, Haywood K, Fitzpatrick R (2006) Impact of patientreported outcome measures on routine practice: a structured review. J Eval Clin Pract 12:559-568 
12. Santana M-J, Feeny D (2014) Framework to assess the effects of using patient-reported outcome measures in chronic care management. Qual Life Res 23:1505-1513

13. Valderas JM, Kotzeva A, Espallargues M, Guyatt G, Ferrans CE, Halyard MD et al (2008) The impact of measuring patientreported outcomes in clinical practice: a systematic review of the literature. Qual Life Res 17:179-193

14. Tan KK, Tan IJ, Lim FS, Koh DC, Tsang CB (2011) The anatomy of failures following the ligation of intersphincteric tract technique for anal fistula: a review of 93 patients over 4 years. Dis Colon Rectum 54(11):1368-1372

15. Liu WY, Aboulian A, Kaji AH, Kumar RR (2013) Long-term results of ligation of intersphincteric fistula tract (LIFT) for fistula-in-ano. Dis Colon Rectum 56(3):343-347

16. Bleier JIS, Moloo H, Goldberg SM (2010) Ligation of the intersphincteric fistula tract: an effective new technique for complex fistulas. Dis Colon Rectum 53(1):43-46

17. Shanwani A, Nor AM, Amri N (2010) Ligation of the intersphincteric fistula tract (LIFT): a sphincter-saving technique for fistulain-ano. Dis Colon Rectum 53(1):39-40

18. Abcarian AM, Estrada JJ, Park J, Corning C, Chaudhry V, Cintron J, Prasad L, Abcarian H (2012) Ligation of intersphincteric fistula tract: early results of a pilot study. Dis Colon Rectum 55(7):778-782

19. Wallin UG, Mellgren AF, Madoff RD, Goldberg SM (2012) Does ligation of the intersphincteric fistula tract raise the bar in fistula surgery? Dis Colon Rectum 55(11):1173-1178

20. Bastawrous A, Hawkins M, Kratz R, Menon R, Pollock D, Charbel J, Long K (2015) Results from a novel modification to the ligation intersphincteric fistula tract. Am J Surg 209(5):793-798

21. Schulze B, Ho YH (2015) Management of complex anorectal fistulas with seton drainage plus partial fistulotomy and subsequent ligation of intersphincteric fistula tract (LIFT). Tech Coloproctol 19(2):89-95

22. Parthasarathi R, Gomes RM, Rajapandian S, Sathiamurthy R, Praveenraj P, Senthilnathan P, Palanivelu C (2016) Ligation of the intersphincteric fistula tract for the treatment of fistula-in-ano: experience of a tertiary care centre in South India. Colorectal Dis 18(5):496-502
23. Chen HJ, Sun GD, Zhu P, Zhou ZL, Chen YG, Yang BL (2017) Effective and long-term outcome following ligation of the intersphincteric fistula tract (LIFT) for transsphincteric fistula. Int J Colorectal Dis 32(4):583-585

24. Xu Y, Tang W (2017) Ligation of intersphincteric fistula tract is suitable for recurrent anal fistulas from follow-up of 16 months. Biomed Res Int 2017:3152424

25. Sun XL, Wen K, Chen YH, Xu ZZ, Wang XP (2019) Long-term outcomes and quality of life following ligation of the intersphincteric fistula tract for high transsphincteric fistulas. Colorectal Dis 21(1):30-37

26. Kontovounisios C, Tekkis P, Tan E, Rasheed S, Darzi A, Wexner SD (2016) Adoption and success rates of perineal procedures for fistula-in-ano: a systematic review. Colorectal Dis. 18(5):441-458

27. Vergara-Fernandez O, Espino-Urbina LA (2013) Ligation of intersphincteric fistula tract: what is the evidence in a review? World J Gastroenterol 19(40):6805-6813

28. van Onkelen RS, Gosselink MP, Schouten WR (2012) Is it possible to improve the outcome of transanal advancement flap repair for high transsphincteric fistulas by additional ligation of the intersphincteric fistula tract? Dis Colon Rectum 55(2):163-166

29. Visscher AP, Felt-Bersma RJ (2015) Endoanal ultrasound in perianal fistulae and abscesses. Ultrasound Q 31(2):130-137

30. Mitalas LE, van Onkelen RS, Monkhorst K, Zimmerman DD, Gosselink MP, Schouten WR (2012) Identification of epithelialization in high transsphincteric fistulas. Tech Coloproctol 16(2):113-117

31. 't Hoen LA, Utomo E, Schouten WR, Blok BF, Korfage IJ (2017) The fecal incontinence quality of life scale (FIQL) and fecal incontinence severity index (FISI): validation of the Dutch versions. Neurourol Urodyn 36:710-715

Publisher's Note Springer Nature remains neutral with regard to jurisdictional claims in published maps and institutional affiliations. 